\title{
The COVID-19 Pandemic and Corporate Dividend Policy
}

\author{
Georg Cejnek \\ ZZ Vermögensverwaltung \\ georg.cejnek@zzgmbh.at \\ Otto Randl \\ WU (Vienna University of Economics and Business) Department of Finance, Accounting, and Statistics \\ Josef Zechner (ii) \\ WU (Vienna University of Economics and Business) Department of Finance, Accounting, and Statistics \\ josef.zechner@wu.ac.at (corresponding author)
}

\begin{abstract}
This article shows that, for major equity markets, the proportion of index values attributable to the first 5 years of dividends dropped substantially in the first quarter of 2020 and that this drop was not reversed by the end of the year. In the cross section, this breakdown of dividend smoothing due to COVID-19 was less severe for firms with higher operating cash flows and more positively coskewed stock returns, and it was more pronounced for those with higher leverage and in the financial sector. Heavy dividend cutters also experienced a substantial increase in exposure to systematic risk.
\end{abstract}

\section{Introduction}

Dividend policy does not matter in frictionless markets, as shown by Modigliani and Miller (1961). Under certain assumptions, this holds even when dividend policy is allowed to affect investment (e.g., Brennan (1971)). In this case, firms can reduce current dividends, compound forward the resulting free cash flows, and pay them out later, without affecting firm value. The empirical evidence does not accord well with such a frictionless world. Investors seem to care about corporate dividend decisions, as witnessed by numerous studies of stock price reactions to dividend announcements and by popular portfolio strategies based on various aspects of corporate dividend policy. Managers also seem to attach great importance to their dividend decisions, as documented in Brav, Graham, Harvey, and Michaely (2005).

Despite this, our knowledge of the determinants of corporate dividend policies is still quite limited. One of the few stylized facts about dividend decisions that

We thank Harry DeAngelo, Ran Duchin (editor), Andrei Gonçalves, Mark Grinblatt, Jarrad Harford (editor), Jonathan Karpoff, Alessandro Melone, Neal Stoughton, Jules van Binsbergen, Michael Weber, Alex Weissensteiner, Youchang Wu, and participants of the JFQA COVID-19 symposium for valuable comments. Miklós Verebélyi has provided excellent research assistance. 
many scholars and practitioners agree on is dividend smoothing: Firms seem to base their current dividend on the previous dividend, and they only slowly adjust toward a long-term payout ratio. In fact, Brav et al. (2005) document that financial executives view the importance of maintaining dividend levels at par with investment decisions. This is consistent with an intermediary role that firms play for their shareholders, providing them with projectable income streams.

Although there is substantial empirical evidence on the smoothness of the time series of dividends, important dimensions remain unexplored. In particular, we know very little about dividend behavior in extreme states of the world. Do firms abandon dividend smoothing in such states? Are there cross-sectional differences in dividend smoothing in times of economic turmoil, and, if yes, to which firm characteristics are they related? Can dividend behavior in extreme states offer an explanation for the high risk premia on dividend futures with shorter maturities? Do dividend bans in crisis states have plausible effects on firms' cost of capital?

The dramatic economic impact of the COVID-19 pandemic allows us to shed some light on these questions. To this end, we use dividend futures to estimate the risk-return characteristics of dividend claims with different maturities. Our main findings are as follows: First, we document that the values of near-term dividends are indeed much less risky than stock prices in the time period leading up to the COVID-19 pandemic, as suggested by the existing literature on dividend smoothing. However, in the wake of COVID-19, near-term dividend expectations declined dramatically and only recovered partially by the end of 2020 . As a result, the fraction of the overall equity market value due to near-term dividends dropped substantially. Consistent with this result, we also document that near-term dividend futures exhibit negative coskewness betas, that is, that they perform particularly poorly in periods with extreme market returns. Second, there is significant heterogeneity in the adverse effect of COVID-19 on the value of short-term dividends relative to stock prices. The disproportionate adverse effect of COVID-19 on the value of near-term dividends increases with firms' debt ratios, with the exposure of their operations to COVID-19, and with regulatory measures restricting dividends, which especially applied to the financial sector. In contrast, firms with higher operating cash flows (relative to total assets) and with more positively coskewed stock returns experienced smaller reductions in the value of near-term dividends. Finally, we document that heavy dividend cutters experienced substantially increased exposures to systematic risk.

Our article is closely related to 2 strands of literature. First, we contribute to the literature on dividend smoothing, starting with the seminal article by Lintner (1956). More recent important contributions to this research include Brav et al. (2005), Leary and Michaely (2011), Wu (2017), and Bonaimé, Harford, and Moore (2020). Our article differs by focusing on the extent to which dividend smoothing also occurs in disaster periods, such as the COVID-19 year 2020.

Second, our article also builds on the literature regarding the term structure of equity returns, which was summarized and extended by van Binsbergen and Koijen (2017). Several articles in this literature exploit dividend futures prices to estimate risk-return characteristics of dividend claims with different maturities. ${ }^{1}$ One of the

\footnotetext{
${ }^{1}$ In an interesting recent contribution to this literature, Gormsen and Koijen (2020) use prices of dividend futures in the ongoing COVID-19 crisis to back out revisions of dividend and GDP growth expectations.
} 
puzzling findings is the high risk premium associated with short-maturity contracts. This is despite the fact that dividends tend to be stable for individual firms and even more so for an equity index. In particular, this seems to be the case for the shortest maturities, where dividends have often already been announced by firms. Cejnek and Randl (2016) propose a downside risk explanation for risk premia on short-term dividend contracts. More generally, Schneider, Wagner, and Zechner (2020) argue that coskewness may explain low-risk anomalies. We also use dividend futures data for our analysis of dividend dynamics in response to the COVID-19 pandemic. We show that, despite the fact that in normal times, futures prices of near-term dividends are smooth and less risky than their corresponding equity prices, they seem to exhibit more downside risk than overall stock prices in extreme states. Thus, we contribute to the literature on the term structure of equity returns by providing evidence on the comovement of the value of near-term dividends with the market in times of distress, which is closely related to the notion of coskewness and sheds light on the puzzling risk-return characteristics of near-term dividend futures contracts.

The rest of the article is structured as follows: Section II provides information about the relevant features of the market for corporate dividends and describes the data. Section III analyzes the joint dynamics of equity indices and dividend futures during normal times and during the COVID-19 pandemic, whereas Section IV provides cross-sectional evidence. Section $V$ analyzes the effects of regulation as well as the relation of dividend dynamics to changes in exposure to systematic risk. Various robustness analyses are provided in Section VI, and Section VII concludes.

\section{Institutional Background and Data}

In this section, we first present the features of the market for dividends that are particularly relevant for our analysis, and then we describe the data. ${ }^{2}$

\section{A. The Market for Dividends}

As first suggested by Brennan (1998), claims on dividends became actively traded among market participants at the onset of this millennium, allowing them to hedge their dividend risk. More importantly from an academic perspective, though, traded dividend claims enable researchers to impute market-implied expectations for dividend levels and also to infer unexpected dividend growth by comparing realized dividend levels to previous market-implied expectations. Since traded dividend claims exist mainly in the form of over-the-counter (OTC) dividend swaps and exchange listed dividend futures, the implied dividend expectations are net of any risk premia (i.e., under the risk-neutral measure).

Dividend derivatives usually feature annual maturities and are available for maturities that reach several years into the future, creating a whole term structure of risk-adjusted, market-implied dividend expectations. The underlyings of the most liquid dividend derivatives are equity indices, such as the Euro Stoxx 50, the FTSE 100, the Nikkei 225, and the S\&P 500. For these index dividend swaps (or futures),

\footnotetext{
${ }^{2}$ For a comprehensive description of institutional details of the market for dividends, see, for example, Manley and Mueller-Glissmann (2008), van Binsbergen, Hueskes, Koijen, and Vrugt (2013), or Gonçalves (2021).
} 
the payoffs are defined by aggregating the dividends paid by each index constituent over the whole maturity year, taking into account the appropriate index weights of individual companies.

In addition, there exist single stock dividend derivatives in the form of both OTC swaps and exchange listed futures. The trading activity of single stock dividend derivatives is more concentrated in the OTC markets, though. For these instruments, the corresponding underlying is the aggregate dividend paid by the company over the maturity year. Although single name dividend derivatives are also available for several annual maturities, they usually do not offer maturities as far into the future as index dividend derivatives.

In addition, sector dividend futures are also available and offer investors exposure to aggregate dividends paid by constituents of a sector subindex. The most important and most liquid traded sector dividend futures listed at the EUREX is the Euro Stoxx Banks dividend futures. Dividend derivatives on the Euro Stoxx 50 are especially interesting from a research perspective, because there are contracts available on the index, on the banks subindex, ${ }^{3}$ and on all single stock dividends of the index constituents. This allows us to augment time-series analyses of the contracts on the market index with cross-sectional information, without introducing any obvious bias arising from sample misrepresentation. For the FTSE 100, there is currently a subset of 27 companies that have listed single stock dividend futures (on the EUREX), and for the S\&P 500, there are 21, albeit with much less liquidity than for the other indices mentioned. ${ }^{4}$

\section{B. Data}

For the present article, we utilize data on exchange-listed index dividend futures on the Euro Stoxx 50, the FTSE 100, and the S\&P 500 with maturities ranging from 2018 to 2026, and the Euro Stoxx Banks index from 2018 to 2025. We further obtain data on exchange-listed single stock dividend futures for all Euro Stoxx 50 constituents and a subset of 27 FTSE 100 members that have single stock dividend futures listed on the EUREX. In this case, we focus on maturities 2020 and 2021 only. We augment these data by the corresponding equity index prices and single-name equity prices as well as risk-free rates, using zero-coupon yields for German Sovereign Bonds in EUR, U.K. Sovereign Bonds in GBP, and Treasury Actives in USD, with 3 months and 1-5 years maturities. We retrieve time series data from Bloomberg for the period from Mar. 2017 to Dec. 2020. Moreover, we download the following accounting-based characteristics for individual firms from Bloomberg as of end of year 2019: operating cash flow, total assets, ratio of total debt to total book capital, ratio of short-term debt to long-term debt, ratio of retained earnings to total assets, and ratio of cash and equivalents to short-term debt. We obtain realized dividends for European and U.K. firms from Bloomberg and realized dividend levels from S\&P 500 constituents from the merged Center for Research in Security Prices (CRSP) and Compustat database via Wharton Research Data Services (WRDS). We collect for Euro Stoxx 50 member companies data on

\footnotetext{
${ }^{3}$ The Euro Stoxx Banks index is not a subindex of the Euro Stoxx 50 index, but both are subindices of the broader Euro Stoxx index that comprises liquid companies of 11 Eurozone countries.

${ }^{4}$ See the EUREX website for trading statistics of dividend futures.
} 
the SIC classification and the geographical distribution of long-term assets from Refinitiv Eikon. Finally, regional COVID-19 cases are from the WHO.

\section{Dividends in Normal Times and in Times of Disaster}

In this section, we analyze the joint dynamics of equity indices and the value of dividend futures during normal times and during the onset of COVID-19. We start by regressing weekly returns of the shortest 2 index dividend futures contracts on the market for the period from Mar. 2017 to Feb. 2020. Table 1 contains the regression results, revealing that betas are substantially below 1 , in the range of $0.21-0.7$. These results confirm that firms engage in dividend smoothing in normal times. ${ }^{5}$

However, the onset of the COVID-19 pandemic provides evidence that market betas of dividend futures during normal times do not adequately capture dividend risk. Figure 1 presents the performance of the Euro Stoxx 50 and the S\&P 500 over the period from Jan. 1, 2019 to Dec. 18, 2020, compared to their respective index dividend futures with maturities 2020 and 2021. The performance of equity indices is hereby defined in excess of the market-specific risk-free rate. Figure 1 reveals interesting patterns in the dynamics of the index levels and the respective index dividend futures. Just before the onset of the COVID-19 pandemic, and even during the time when information about the pandemic first came out in Jan. and early Feb. 2020, the values of the respective dividend futures evolve much more smoothly than the indices themselves. This is consistent with the observed market betas below 1 for the period before the crisis. In fact, dividend futures have shown some resilience, in both Europe and the United States, even when stock markets already started their decline. However, this pattern changes abruptly in Mar. 2020, when the United States declared a national emergency and Italy announced its first national

TABLE 1

Betas of Dividend Futures on Equity Indices

Table 1 reports the estimates of OLS regressions $r x_{i, t}=\alpha_{i}+\beta_{i} r x_{m, t}+\varepsilon_{i, t}$, where assets $i$ are dividend futures with maturities 2020 and 2021, and markets $m$ are the corresponding stock market indices. We estimate but do not report alphas. Data are at weekly frequency from Mar. 2017 to Feb. 2020, with returns calculated for weeks ending on Tuesdays. Source: Bloomberg.

\begin{tabular}{lccc} 
& \multicolumn{1}{c}{$\beta$} & SE & Adj. $R^{2}$ \\
\cline { 2 - 3 } $\begin{array}{l}\text { Euro Stoxx 50 } \\
\text { Index dividend future 2020 }\end{array}$ & & 0.0313 & 0.5842 \\
Index dividend future 2021 & 0.4624 & 0.0322 & 0.7544 \\
S\&P 500 & 0.7031 & & \\
Index dividend future 2020 & & 0.0283 & 0.2663 \\
Index dividend future 2021 & 0.2139 & 0.0356 & 0.3348 \\
FTSE 100 & 0.3167 & & 0.2164 \\
Index dividend future 2020 & & 0.0379 & 0.3314 \\
Index dividend future 2021 & 0.2511 & 0.0444 & \\
\hline
\end{tabular}

\footnotetext{
${ }^{5}$ Betas of index dividend futures tend to increase with time to maturity, so the reported coefficients likely overestimate the betas of short-term contracts. In Table A1 in Appendix A, we report the betas of synthetic constant-maturity dividend futures that are considerably lower, providing even stronger evidence of smooth dividend expectations.
} 


\section{FIGURE 1}

\section{Performance of Equity Indices and Dividend Futures}

Figure 1 shows market excess return indices in comparison to the corresponding dividend futures with maturities 2020 and 2021 from Jan. 1, 2019 to Dec. 18, 2020 (maturity of the 2020 dividend contracts). Graph A is for the Euro Stoxx 50; Graph B for the S\&P 500. Source: Bloomberg.
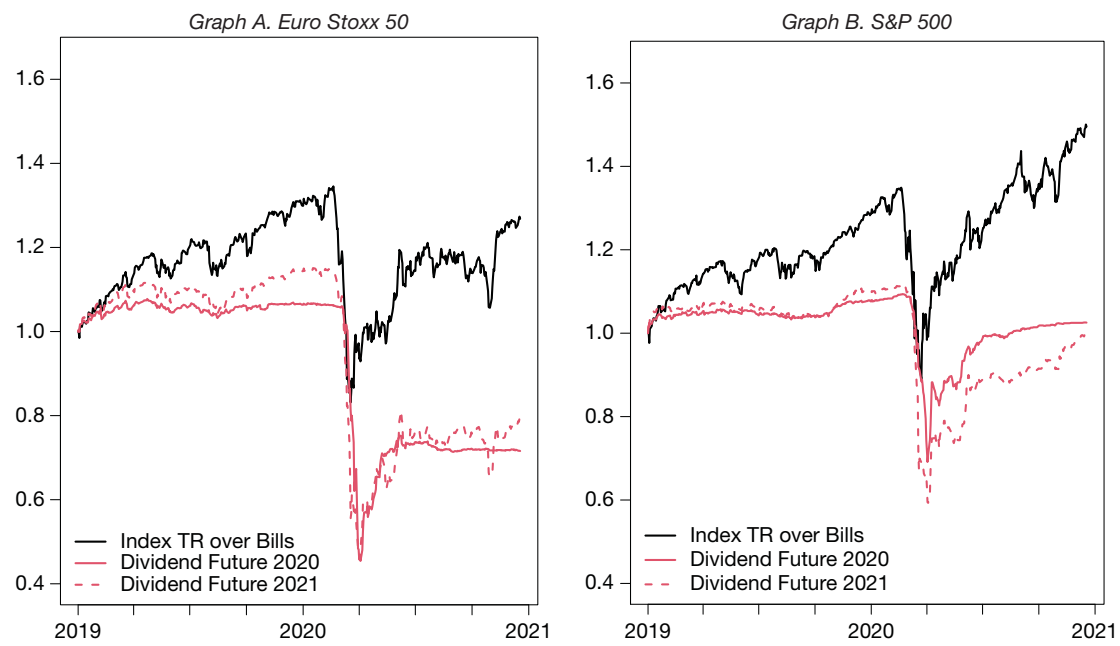

lockdown. During this time, dividend futures experienced sharp declines, with even more pronounced drawdowns (DD) than their corresponding market indices. ${ }^{6}$ Thus, despite robust 2019 earnings, many companies announced or were expected to announce dividend cuts to protect their liquidity.

We next provide evidence on the dynamics of the present values of synthetic dividend futures with constant maturities from 1 to 5 years, as a fraction of their respective index values. We hereby aggregate the present values of the various contracts and express them as a fraction of their respective index values, as shown in Figure 2. For any date $t$ in calendar year $y$ (before the dividend index reset date in December), we calculate the value of the synthetic $n$-year constant-maturity dividend contract as a weighted average of 2 adjacent annual contracts with maturities $y+n-1$ and $y+n$, where the weight of the nearer contract is the time difference from $t$ to the index reset date, expressed as a fraction of a year. To obtain present values of synthetic futures contracts, we discount using the zero-coupon government bonds curve of the reference market.

As shown in Figure 2, before the crisis, investors valued the first 5 years of dividends at about $17 \%$ and $10 \%$ of the index value for the Euro Stoxx 50 and the

\footnotetext{
${ }^{6}$ The price indices of the Euro Stoxx 50, S\&P 500, and FTSE 100 stock indices experience $10 \%$ cumulative drawdowns from their previous 2020 highs already on Feb. 27, 2020. As discussed by Ramelli and Wagner (2020), the COVID-19 outbreak was declared a U.S. national emergency on Mar. 13. Only at about this time, specifically on Mar. 12 for the FTSE 100, and on Mar. 16 for both the Euro Stoxx 50 and S\&P 500, did the dividend futures with maturity 2020 experience a $10 \%$ drawdown from their highs. However, as shown in Figures 1 and 7, the subsequent price movements during the COVID-19 crisis were much more severe for the dividend futures than for the corresponding stock market indices.
} 


\section{FIGURE 2}

\section{Present Value of Nearby Dividends}

Figure 2 shows the (cumulative) present values of the dividend futures with constant maturities from 1 to 5 years, expressed as a fraction of index values. We construct constant-maturity contracts as time-weighted averages of adjacent annual dividend futures. Graph A is for the Euro Stoxx 50; Graph B for the S\&P 500. Source: Bloomberg.
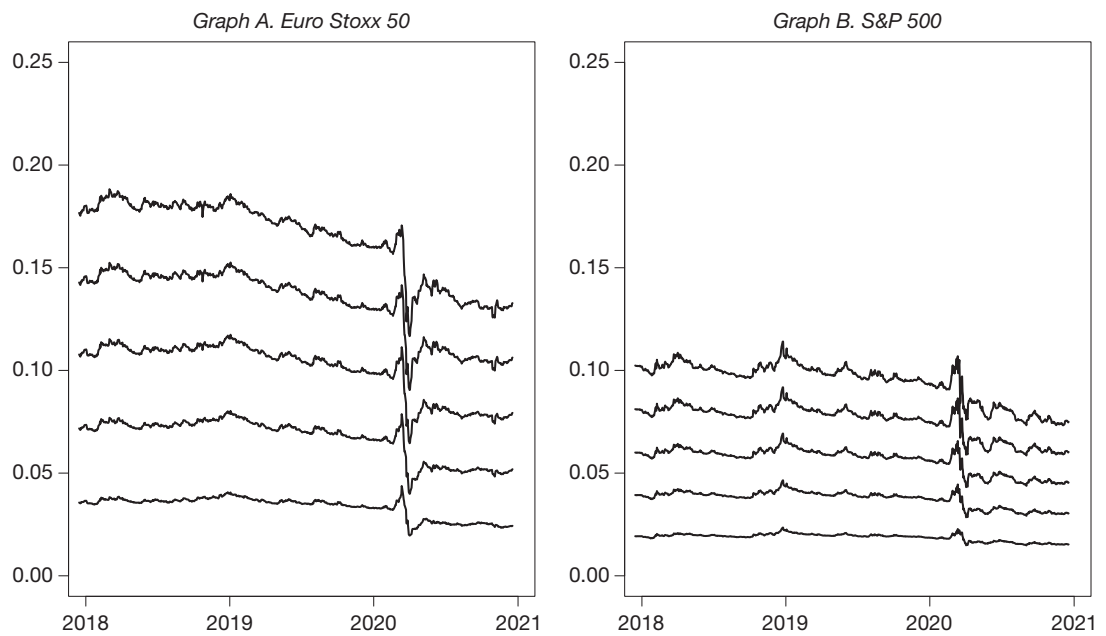

S\&P 500, respectively. Strikingly, all lines show a spike just around the onset of the crisis. This is consistent with investors' initial expectations that near-term dividends would turn out more stable than stock prices. However, shortly after the onset of the crisis, these dynamics are reversed, and the ratios exhibit a sharp drop, implying that investors expected a sharper drop in near-term dividends than the corresponding drop in share prices. ${ }^{7}$ In fact, even by the end of the year 2020 , the ratio of the present value of nearby dividends to index levels has not recovered. Overall, Figure 2 does not accord well with the notion that investors expected dividend smoothing, once the extent of the COVID-19 pandemic became apparent. To the contrary, market prices indicate that the percentage drop in the present value of cuts in near-term dividends during the onset of the COVID-19 pandemic exceeds that of the overall drop in stock prices.

The evidence so far suggests that claims on near-term dividends perform particularly poorly in states of extreme market turmoil. If this is indeed the case, returns on near-term dividend claims should exhibit negative coskewness with market returns and an interesting relation between corporate finance decisions (i.e., to cut near-term dividends in response to a disaster), and the pricing of corporate securities emerges. As first shown by Kraus and Litzenberger (1976) and, more recently, by Harvey and Siddique (2000), investors may require compensation for coskewness of returns. In accordance with this insight, Cejnek and Randl (2016) discuss a downside-risk explanation for the observed high risk-adjusted returns of short-maturity dividend futures, and Schneider et al. (2020) show that a wide range of

\footnotetext{
${ }^{7}$ The spike in Figure 2 occurs around Mar. 12 for the Euro Stoxx 50 and around Mar. 16 for the S\&P 500.
} 


\section{FIGURE 3}

\section{Coskewness}

Figure 3 shows the coskewness betas $\beta_{i}^{\text {cosk }}$ of constant-maturity dividend futures with maturities from 1 to 5 years, obtained from a regression of weekly dividend futures excess returns on squared market excess returns: $r x_{i, t}=\alpha_{j}+\beta_{i}^{\text {cosk }} r x_{m, t}^{2}+\varepsilon_{i, t}$. We construct constant-maturity contracts as time-weighted averages of adjacent annual dividend futures. Graph $\mathrm{A}$ is for the Euro Stoxx 50, Graph B for the S\&P 500. Source: Bloomberg.
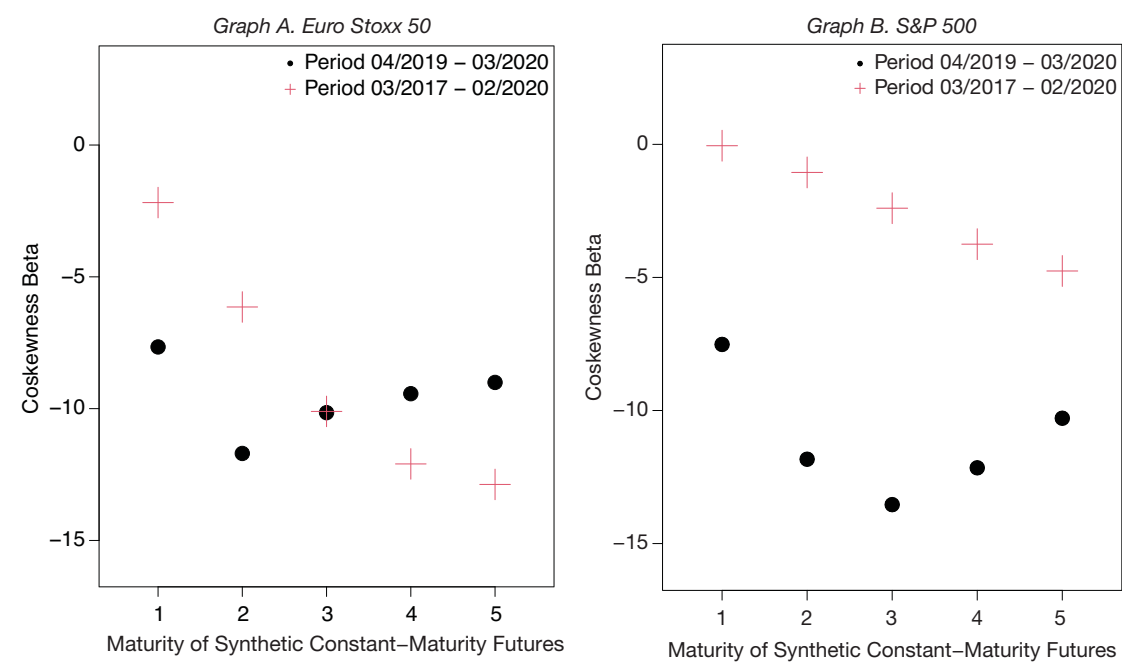

apparent low-risk anomalies can be explained by negative residual return coskewness. We therefore analyze coskewness of index dividend contracts with maturities of up to 5 years, both for the United States and for Europe. To this end, we estimate coskewness betas by regressing constant-maturity dividend futures excess returns on squared market excess returns as shown in equation (1).

$$
r x_{i, t}=\alpha_{i}+\beta_{i}^{\text {cosk }} r x_{m, t}^{2}+\varepsilon_{i, t} .
$$

The results are shown in Figure 3 for 2 estimation periods, using weekly data. The crosses represent estimates for the period from Mar. 2017 to Feb. 2020 which corresponds to the precrisis period analyzed in Table 1 . The black circles are for the period from Apr. 2019 to the end of Mar. 2020, which includes the weeks with the most severe effects from the COVID-19 crisis on the stock market. We notice that coskewness betas are all negative. This holds for both the United States and Europe, for both estimation periods and for all dividend futures maturities that we consider. Coskewness betas are modest when we use historical data up to Feb. 2020, especially for short maturities. However, when the turmoil period of Mar. 2020 is included, (negative) coskewness betas jump. Interestingly, for this period, it is the 2- and 3-year maturities which exhibit the most pronounced negative coskewness. Extreme market movements during this period appear associated with investors' expectation of pronounced dividend cuts, in particular for the not-too-distant future.

The results above are consistent with the high average returns (and alphas) of dividend claims reported in the literature, since investors may require additional compensation for coskewness risk. They suggest that the liquidity that dividends 
represent for shareholders disappears precisely in states, in which liquidity is likely to be particularly valuable. Thus, the high risk premia on low-beta dividend futures in recent years may be a reflection of the risk of rare but substantial cuts in expected dividends, associated with large market moves.

\section{Cross-Sectional Evidence}

We have so far mainly focused on the dynamics of the valuation of near-term dividends of the aggregate market. We now complement this analysis by exploiting cross-sectional data, using returns on single stock dividend futures and their corresponding stock returns for constituents of the Euro Stoxx 50 index. Table 2 provides summary statistics of the cumulative drawdowns of Euro Stoxx 50 member stocks as well as the corresponding single stock dividend futures with maturities 2020 and 2021. Results are provided both for the first quarter of 2020 as well as for the entire year 2020. As shown in Table 2, mean drawdowns as well as third quartile and maximum drawdowns for short-term dividend futures are more severe than those of the corresponding stock prices over both sample periods.

We next regress the cumulative drawdowns of single stock dividend futures (2020 maturity) during the first quarter of 2020 on the corresponding stock drawdowns. Table 3 shows that the regression yields a highly significant slope coefficient of 1.35 , which is 1.5 standard errors above 1 . In addition, the positive alpha of the regression indicates that the onset of the pandemic had an effect on dividend futures, independent of the drawdowns of the corresponding stock prices. We also estimate similar regressions for the 2021 single stock dividend futures and using the entire year 2020 as the observation period. Even though point estimates of the beta coefficients are lower for these specifications, they are always less than 1 standard error from 1, indicating that short-dated dividend futures bear surprisingly large systematic risk in times of crises. In addition to betas being statistically indistinguishable from 1, the regressions all have a positive and significant intercept. Thus, although near-term dividends are considered to be very sticky, their futures prices exhibit large drawdowns in times of crises. Figure 4 visualizes this point for the regression in the first row of Table 3 . Several single stock dividend futures reflect

TABLE 2

\section{Drawdown Summary Statistics}

\begin{tabular}{|c|c|c|c|c|c|c|}
\hline & Min & P25 & Median & Mean & $\underline{\mathrm{P} 75}$ & Max \\
\hline \multicolumn{7}{|l|}{ Cumulative Drawdown During Q1 2020} \\
\hline Single stock 2020 dividend futures & 0.00 & 0.30 & 0.47 & 0.51 & 0.65 & 1.00 \\
\hline Single stock 2021 dividend futures & 0.12 & 0.35 & 0.49 & 0.51 & 0.66 & 1.00 \\
\hline Euro Stoxx 50 member stocks & 0.02 & 0.15 & 0.28 & 0.27 & 0.36 & 0.55 \\
\hline \multicolumn{7}{|c|}{ Cumulative Drawdown During the Year 2020} \\
\hline Single stock 2020 dividend futures & -0.29 & -0.01 & 0.07 & 0.30 & 0.54 & 1.00 \\
\hline Single stock 2021 dividend futures & -0.34 & 0.06 & 0.17 & 0.28 & 0.51 & 0.90 \\
\hline Euro Stoxx 50 member stocks & -0.48 & -0.05 & 0.08 & 0.07 & 0.21 & 0.47 \\
\hline
\end{tabular}


TABLE 3

Cross-Sectional Drawdown Regressions

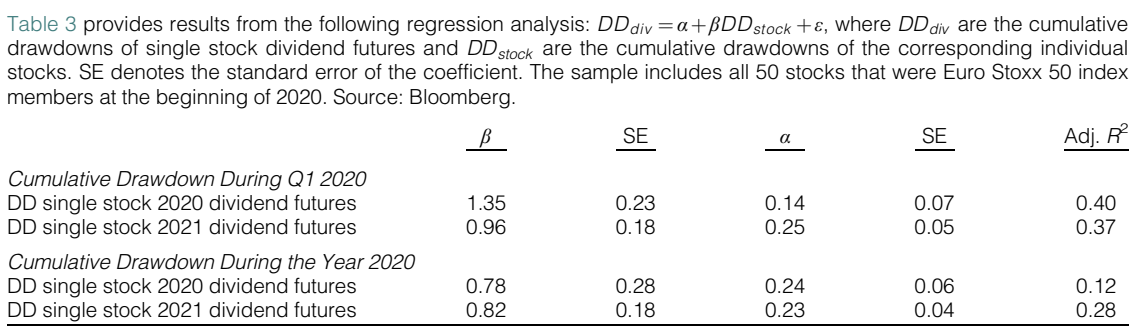

FIGURE 4

Dividend Futures Versus Equity Drawdowns in 2020:Q1

The scatterplot in Figure 4 shows cumulative drawdowns of single stock dividend futures on the $y$-axis and the corresponding stock drawdowns on the $x$-axis. The dark line is the fitted regression slope. Source: Bloomberg.

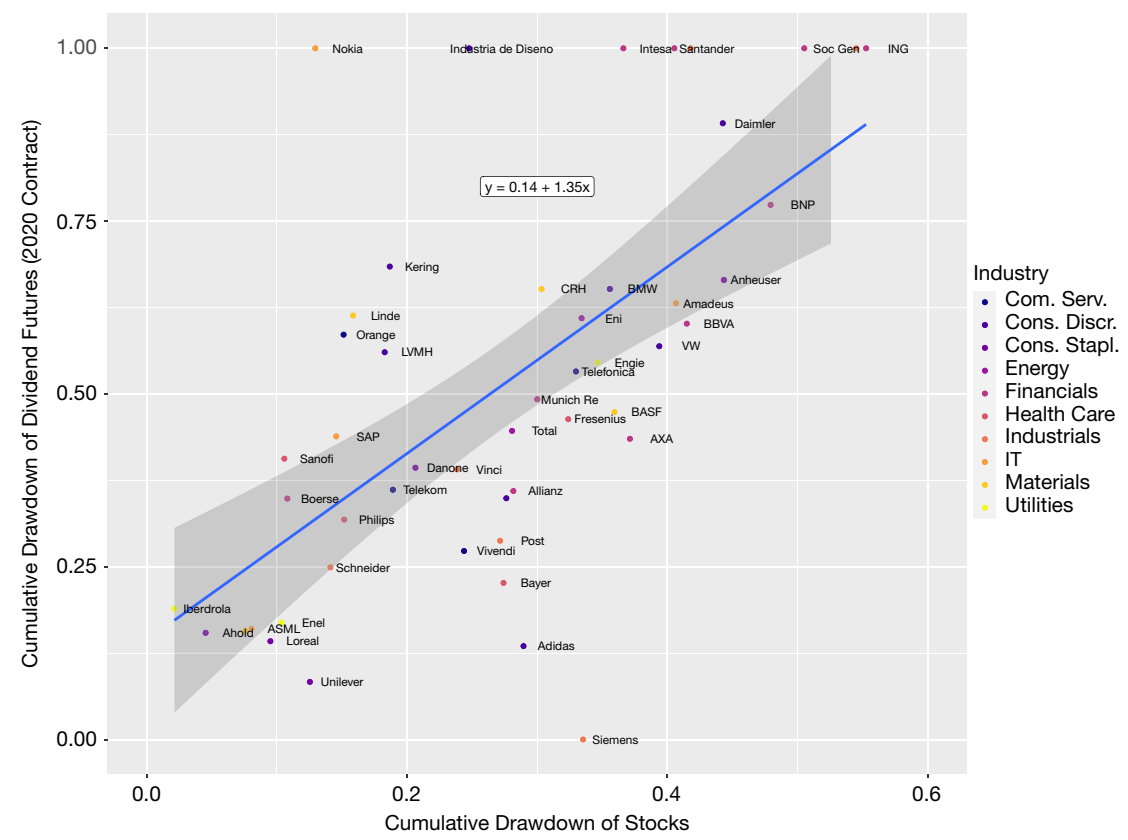

expectations of complete dividend cuts, including some firms with only moderate stock price losses, such as Nokia.

We next provide evidence to what extent the large cuts in expected dividends over the first quarter of 2020 which are implicit in the drawdowns of dividend futures corresponded to actually realized dividend cuts in 2020 . To investigate this, we focus on the cumulative changes in the values of 2020 futures contracts over the entire year 2020 (the 2020 contracts mature on the third Friday in December). These 


\section{FIGURE 5}

Histograms of Dividend Cuts

Graph A of Figure 5 plots the frequency of actually realized dividend cuts of Euro Stoxx 50 member companies in the year 2020. A value of 1 corresponds to a $100 \%$ cut of dividends relative to the futures-implied expectation at the beginning of the year. Negative values correspond to dividend increases. Graph B plots the frequency of dividend cuts of S\&P 500 member companies, relative to the level of dividends paid in 2019. Values $<-1$ are truncated. Sources: Bloomberg, CRSP, and Refinitiv Eikon.
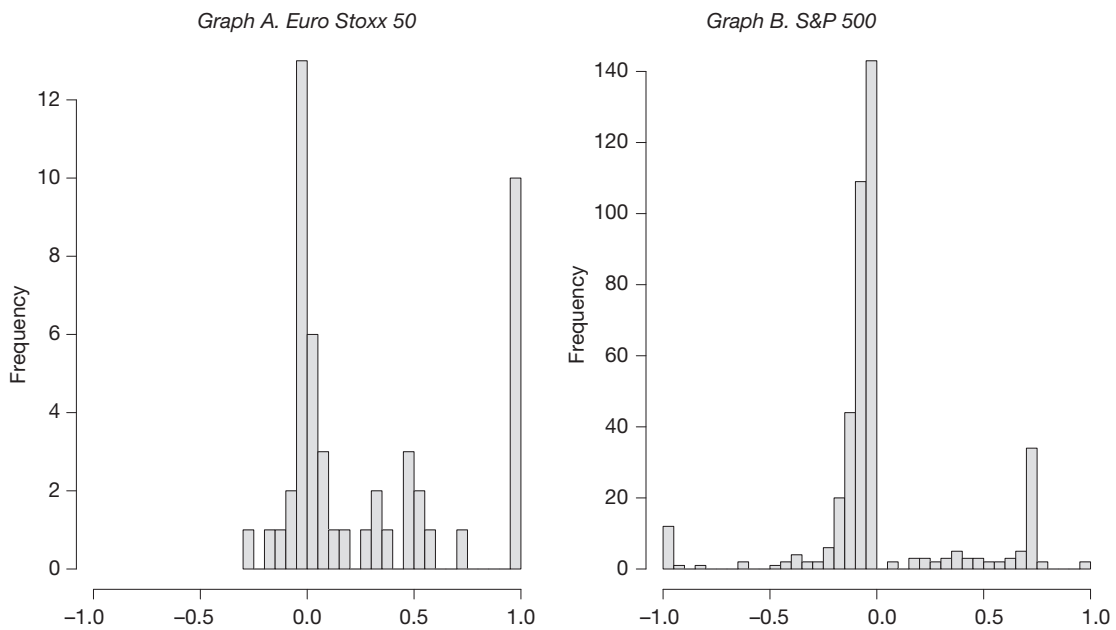

changes reflect the actual dividend cuts relative to the futures-implied expectations at the beginning of the year. We illustrate the results for the constituents of the Euro Stoxx 50 in Graph A of Figure 5. The histogram shows that many firms indeed cut their dividends by a large fraction or even completely. There is significantly more probability mass for firms with positive dividend cuts, and there is a large spike at 1 , indicating a $100 \%$ cut in dividends.

Since there are no liquid single stock dividend futures for U.S. firms, we provide evidence on actual dividend cuts for U.S. firms relative to their dividends in the previous year instead. ${ }^{8}$ Graph B of Figure 5 presents the results for the United States. We also see a substantial number of firms with dividend cuts relative to the previous year's dividends. In fact, there is a large spike at 0.75 , indicating that many firms cut their dividends by $75 \%$ compared to the previous year. For the European data, there is no such spike at 0.75 . Instead, there is a spike at 1 , as discussed previously. This is consistent with the fact that U.S. firms generally pay quarterly dividends, and by the time information about the full extent of the pandemic came out, many first quarter dividends were already paid. Thus, the high fraction of firms cutting by $75 \%$ on an annual basis is comparable to the high fraction of Euro Stoxx 50 member firms that cut by $100 \%$, because these companies usually pay annual dividends, which for most firms would be paid after the first quarter. In conclusion, although dividend futures of many firms eventually recovered and dividends realized closer to the initial expectation (or last year's level in

\footnotetext{
${ }^{8}$ Although a few U.S. firms have dividend futures listed on European exchanges, their data quality is substantially worse than that for Euro Stoxx or FTSE member companies.
} 
the case of the U.S.), for a substantial fraction of firms, the dividend futures drawdowns during the crisis year were actually followed by substantial dividend cuts, which contrast with the notion of dividend smoothness.

\section{Dividend Dynamics During COVID-19 and Firm Characteristics}

Next, we shed some light on the firm characteristics with which the heterogeneity of dividend changes in the wake of COVID-19 is associated. Since we are restricted to a small universe of liquid firm-specific dividend futures, namely the constituents of the Euro Stoxx 50, this subsection does not represent a full-fledged empirical test of firms' dividend policies, but provides some simple analyses that relate firm characteristics to dividend dynamics during the year 2020 .

Our set of explanatory variables is intended to capture firms' flexibility to avoid dividend cuts even in disaster states and is motivated by recent studies on payout policy and financial flexibility, as measured by variables, such as cash and leverage (see, e.g., Bonaimé et al. (2020)) or retained earnings (see, e.g., DeAngelo, DeAngelo, and Stulz (2006)). Specifically, we consider the following variables: total debt to total capital (DEBT), the ratio of short-term debt (below 1 year maturity) to long-term debt (DEBT_MAT), the ratio of retained earnings to total assets (RET_EARN), the ratio of cash and cash equivalents over short-term debt (CASH_RAT), and the ratio of cash flow from operations to total assets (CASH_FLOW). All accounting-based measures are as of Dec. 31, 2019.

In addition, we consider measures of the potential exposure to the COVID-19related market turmoil. To this end, we include the coskewness of individual stock returns with respect to the Euro Stoxx 50 returns (CO_SKEW). The coskewness of individual equity returns with respect to the Euro Stoxx 50 index returns is measured either over the first quarter or the full year 2020, using daily returns, based on the definition in equation (1). We also include a firm-specific direct measure of COVID-19 exposure (COVID_EXP), constructed as follows: For each company, we retrieve the geographical distribution of long-term assets and multiply the fraction of long-term assets in a particular country with the corresponding COVID-19 cases in that country. This weighted average of COVID-19 cases is included to control for direct firm-specific COVID-19 exposure.

In a first step, we correlate the above characteristics with the cumulative drawdown of firms' corresponding 2020 and 2021 single stock dividend futures contracts, respectively, both over the first quarter of the year 2020 and over the full year 2020. Table 4 provides the point estimates of the correlations together with the corresponding $p$-values. The results show that firms' debt ratios are always significantly positively related to dividend drawdowns, except in one specification (the 2021 dividend futures over the first quarter). The drawdown of the 2020 contracts over the first quarter is also significantly and positively related to debt maturity (i.e., shorter debt maturities are associated with larger drawdowns), and to firmspecific COVID-19 exposures, whereas coskewness and operating cash flow over total assets are negatively correlated to dividend drawdowns. Overall, these results accord with economic intuition: more debt, lower cash flow from operations, and more positive (less negative) coskewness of index constituents coincide with larger drawdowns of single stock 2020 dividend futures. 
TABLE 4

\section{Correlation Estimates}

\begin{tabular}{|c|c|c|c|c|c|c|c|}
\hline & DEBT & DEBT_MAT & RET_EARN & CO_SKEW & CASH_RAT & CASH_FLOW & COVID_EXP \\
\hline \multicolumn{8}{|c|}{ Single Stock Dividend Futures 2020 Contracts } \\
\hline Cum DD Q1/2020 & 0.34 & 0.31 & -0.20 & -0.24 & -0.01 & -0.34 & 0.40 \\
\hline$p$-Value & 0.02 & 0.03 & 0.16 & 0.09 & 0.96 & 0.01 & 0.03 \\
\hline Cum DD year 2020 & 0.27 & 0.11 & -0.18 & -0.39 & -0.10 & -0.30 & -0.14 \\
\hline$p$-Value & 0.06 & 0.46 & 0.20 & 0.00 & 0.52 & 0.03 & 0.45 \\
\hline \multicolumn{8}{|c|}{ Single Stock Dividend Futures 2021 Contracts } \\
\hline Cum DD Q1/2020 & 0.19 & 0.02 & -0.16 & -0.21 & 0.01 & -0.12 & 0.13 \\
\hline$p$-Value & 0.19 & 0.90 & 0.28 & 0.15 & 0.97 & 0.42 & 0.49 \\
\hline Cum DD year 2020 & 0.37 & 0.18 & -0.12 & -0.52 & -0.14 & -0.17 & -0.24 \\
\hline$p$-Value & 0.01 & 0.22 & 0.40 & 0.00 & 0.35 & 0.24 & 0.21 \\
\hline
\end{tabular}

To provide additional information about the effect of firm characteristics on actual dividend cuts in the pandemic year of 2020, we also perform regression analyses. To this end, we regress the performance (multiplied by -1 ) of the 2020 single stock dividend contracts over the full year 2020 on the 3 significant characteristics from Table 4: DEBT, CO_SKEW, and CASH_FLOW. We consider this combination of contract maturity and observation period especially interesting, since the corresponding drawdowns are the actually realized dividend cuts measured relative to the dividend expectations at the beginning of the year.

Table 5 presents the results for univariate regressions of realized dividend drawdowns on each of the 3 characteristics. To inform us whether the relation between characteristics and dividend cuts is different for financial firms, we also include a control that interacts the relevant firm characteristic with a dummy variable that is 1 for financials and 0 for companies belonging to other industries. Finally, we also estimate a multivariate regression including all explanatory variables jointly. Although the latter specification may be preferable from an econometric perspective, it is limited by the relatively small cross section, comprising 50 companies (Euro Stoxx 50 members).

As shown in columns 1 and 2 of Table 5, more leverage is associated with larger realized dividend cuts. This effect is stronger for financial companies as can be inferred from the significant interaction term. Furthermore, higher (less negative) coskewness in stock returns is related to less severe dividend drawdowns in the crisis year, both for financials and for the other industries, as shown in the 2 significant coefficients in columns 3 and 4 . Higher cash flows from operations also reduce dividend drawdowns. This is also the case when an interaction term is included to control for any special effects within the financial sector (see columns 5 and 6). In the multivariate setting (see column 7), the coefficient of coskewness is still negative and significant, and debt is still positively related to negative dividend surprises over the year 2020 for financial firms. In conclusion, the regression 
TABLE 5

Realized Dividend Cuts and Firm Characteristics

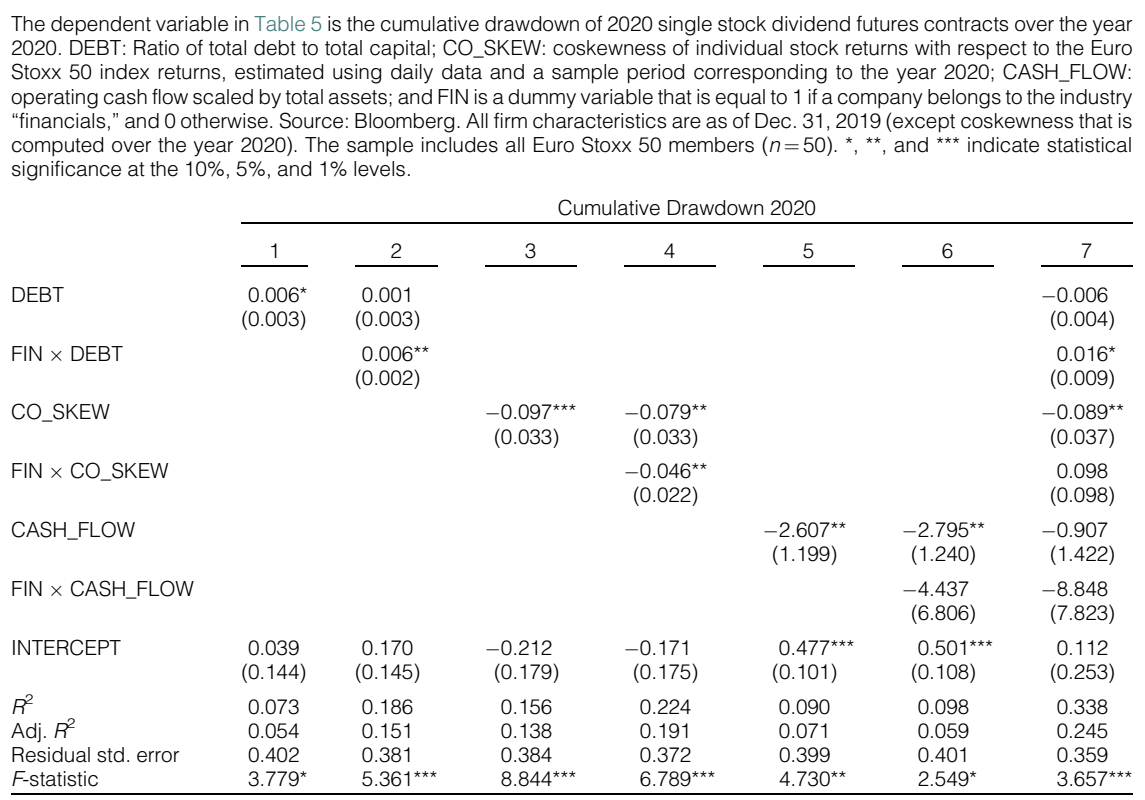

framework confirms the relations between dividend drawdowns and firm characteristics identified previously. Especially, the debt ratio, firms' operating cash flows over total assets, and the coskewness of their stock returns are significantly related to unexpected dividend cuts during 2020.

\section{Impact of Regulation and Cost of Capital}

In several European countries, regulators or government institutions have imposed restrictions on firms' abilities to pay dividends, or they tied government COVID-19 relief programs to dividend cuts. Table 6 summarizes measures to restrict dividend payments in the European Union, Switzerland, the U.K., and the U.S. The table shows that restrictions are most severe for the financial sector and for firms that receive government aid related to the COVID-19 crisis.

To shed light on the potential impact of regulation on actual dividend dynamics in our sample, we explore the subset of firms with substantial dividend cuts in more detail. We hereby consider all firms within the Euro Stoxx 50 that implemented dividend cuts of at least $50 \%$ during the year 2020 relative to their risk-adjusted expectations, given by their respective dividend futures prices at the beginning of January. Table 7 shows that 5 out of the 14 companies with substantial dividend cuts belong to the financial sector, for which ECB recommendations de facto limited possible dividend payments. For the remaining 9 firms in other industries, we found that 1 firm canceled its dividend payments due to a ban after having received a government loan (adidas AG), whereas 2 other firms cut their dividends before 


\section{Summary of COVID-19 Dividend Measures}

\begin{tabular}{|c|c|c|c|}
\hline Country/Region & Summary & Begin & End \\
\hline European Union & $\begin{array}{l}\text { Recommendations to refrain from dividend payment. Most countries } \\
\text { adopted these in the financial sector, also for less significant } \\
\text { institutions. Dividend ban for firms taking COVID-19 relief. }\end{array}$ & Mar. 2020 & Sept. 30, 2021 \\
\hline Switzerland & $\begin{array}{l}\text { Recommendation to postpone dividends and dividend } \\
\text { restrictions for firms applying for COVID-19 relief. }\end{array}$ & Mar. 2020 & \\
\hline U.K. & $\begin{array}{l}\text { Communication to refrain from dividend payments until Dec. 10, } \\
\text { 2020. An "appropriately prudent framework" has been } \\
\text { recommended since then. }\end{array}$ & Mar. 2020 & \\
\hline U.S. & $\begin{array}{l}\text { Large banks had to cap dividend payments. Later dividends } \\
\text { allowed through a specific formula. Dividend ban for COVID-19 } \\
\text { aid firms. }\end{array}$ & June 25, 2020 & Mar. 31, 2021 \\
\hline
\end{tabular}

TABLE 7

Severe Dividend Cuts

Table 7 shows the subset of Euro Stoxx 50 companies that cut their dividends by more than $50 \%$ relative to the futures-implied expectation. Columns show the cumulative drawdown of the 2020 dividend futures, corresponding stock drawdown, industry, and an indication if there was regulatory intervention regarding dividend payments. Essilor initially canceled the 2020 dividend, then later decided to pay but only after the 2020 dividend futures matured. Source: Bloomberg.

\begin{tabular}{|c|c|c|c|c|}
\hline & Dividends & Stocks & Industry & Reg. Intervention \\
\hline Société Générale & 1.00 & 0.45 & Financials & ECB recommendation \\
\hline Airbus & 1.00 & 0.32 & Industrials & Cut before aid \\
\hline ING & 1.00 & 0.26 & Financials & ECB recommendation \\
\hline BNP & 1.00 & 0.18 & Financials & ECB recommendation \\
\hline Intesa & 1.00 & 0.18 & Financials & ECB recommendation \\
\hline Safran & 1.00 & 0.16 & Industrials & Cut before aid \\
\hline Engie & 1.00 & 0.12 & Utilities & None \\
\hline Essilor & 1.00 & 0.04 & Cons. discr. & None \\
\hline Nokia & 1.00 & 0.02 & IT & None \\
\hline Adidas & 1.00 & -0.00 & Cons. discr. & Ban due to state loan \\
\hline Anheuser & 0.72 & 0.20 & Cons. stapl. & None \\
\hline Vinci & 0.55 & 0.15 & Industrials & None \\
\hline Amadeus & 0.54 & 0.21 & IT & None \\
\hline Santander & 0.52 & 0.28 & Financials & ECB recommendation \\
\hline
\end{tabular}

receiving government aid. For 6 out of the 14 companies, we could not find any regulatory intervention as a possible reason for the observed dividend cut.

Given the seemingly important effect of regulation on the dividend payments of financial firms, we compare the price dynamics of dividend claims of banks versus nonbanks in Figure 6. Graph A plots the 2020 dividend futures contract for the Euro Stoxx 50 (black dotted line) and the Euro Stoxx Banks (red (dark) line) indices. The difference is striking; dividend futures of banks crash in the first quarter of 2020 and, in contrast to the broader index, do not recover. Note that although the Euro Stoxx Banks index is not a subindex of the Euro Stoxx 50 index, the banks that are constituents of the latter are also important constituents of the former. We assume that the performance of the Euro Stoxx Banks dividend index equals the performance of a hypothetical Euro Stoxx 50 banks dividend index and impute a synthetic Euro Stoxx 50 nonbanks index, shown as the green (light) line. Although dividends of nonbanks recover more than the aggregate Euro Stoxx 50 index, their level in Dec. 2020 is still approximately 23\% below the level at the start of 2020. 


\section{FIGURE 6}

\section{Sector Indices}

Graph A of Figure 6 compares the Euro Stoxx 50 and Euro Stoxx Banks dividend futures with maturity 2020 with an imputed corresponding nonbanks dividend futures contract. Graph B shows the (cumulative) present values of the Euro Stoxx Banks dividend futures with constant maturities from 1 to 4 years, expressed as a fraction of index values. We construct constantmaturity contracts as time-weighted averages of adjacent annual dividend futures. Source: Bloomberg.
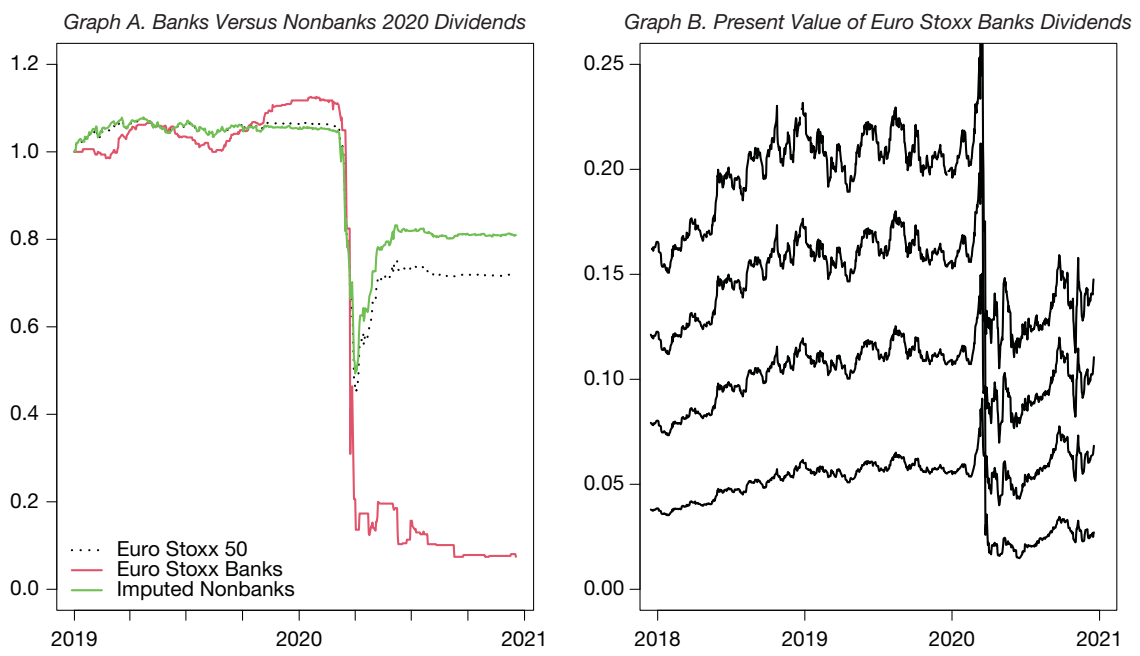

The special status of financials is also shown in Graph B of Figure 6, which plots the cumulative value of the first 4 synthetic constant-maturity dividend futures of the Euro Stoxx Banks index, expressed as a fraction of the index value. A comparison with Figure 2 shows that, immediately prior to the onset of COVID19, in Jan. and early Feb. 2020, the first few years of dividends make up a larger fraction of the bank index than for the Euro Stoxx 50. This may reflect higher risk and/or lower expected growth of the banking sector, compared with the broader index. In Mar. 2020, however, the fractions of the first 4 nearby annual dividend levels over the index value crash, following a brief initial spike, and show only modest recoveries until the end of the year 2020. The severeness of the change is consistent with the market expecting sustained regulatory restrictions on dividend payments.

To assess the impact of dividend cuts on exposures to systematic risk, we calculate firms' market betas to the Euro Stoxx 50 index for the time period from Jan. 1, 2019 to Mar. 20, 2020, and also for the time after the Fed announced its COVID-19 relief programs (i.e., from Mar. 27, 2020 to Dec. 31, 2020). Table 8 illustrates that the median and the mean betas of the constituents of the Euro Stoxx 50 firms did essentially not change over these 2 periods, whereas they increased substantially for firms with severe dividend cuts: The median beta for firms with realized cuts above 50\% during the period from Mar. 27 to Dec. 31, 2020 exceeds the median when estimated for the period from Jan. 1, 2019 to Mar. 20, 2020 by about 0.31 . Similarly, the beta of companies in the heavily regulated financial sector increased. The increases in systematic risk for firms in the 2 subgroups (heavy 
TABLE 8

\section{Change in Betas}

In Table 8, betas are estimated using weekly data for the periods from Jan. 1, 2019 to Mar. 20, 2020, and from Mar. 27, 2020 to Dec. 31,2020 . We report summary statistics for the change in betas for all 50 firms in our sample (Euro Stoxx 50 members as of the end of 2019), financial firms, and firms with the most severe dividend cuts (by at least $50 \%$ relative to the futures-implied expectation as of Jan. 1, 2020). Source: Bloomberg.

\begin{tabular}{|c|c|c|c|c|c|c|}
\hline & Min & P25 & Median & Mean & P75 & Max \\
\hline \multicolumn{7}{|c|}{$\Delta \beta$ Subsequent to COVID-19 Crash } \\
\hline All 50 & -0.516 & -0.135 & -0.002 & 0.091 & 0.267 & 1.148 \\
\hline Financials & -0.089 & 0.210 & 0.305 & 0.316 & 0.412 & 0.720 \\
\hline Severe cuts & -0.160 & 0.060 & 0.310 & 0.388 & 0.687 & 1.148 \\
\hline
\end{tabular}

dividend cutters and financials) are statistically significant with $p$-values below 0.001 for heavy dividend cutters and 0.015 for financials, respectively. These $p$-values are obtained from a bootstrap simulation where changes of betas of the subgroup are compared to the whole distribution of beta changes derived from randomly assigning subgroups of equal size from the overall Euro Stoxx 50 universe 100,000 times. Since we cannot control for possible changes in firm leverage in the wake of the crisis, the documented increase in betas following dividend cuts is only indicative for increases in firms' overall cost of capital. However, severe dividend cuts, either voluntary or imposed by regulators, were indeed related to higher systematic risk of the corresponding companies' equity.

\section{Robustness}

\section{A. Evidence for the U.K.}

Figure 7 provides evidence that our main findings are also supported by U.K. data. As shown, FTSE 100 dividend futures prices with maturities 2020 and 2021 exhibit a more severe crash than the corresponding equity index. The drawdown reaches its bottom in early April (compared to the end of March for the Euro Stoxx 50). The cumulative present value of the first 5 constant-maturity dividend contracts is reduced by about $5 \%$ of the index value as a result of the COVID-19 crisis. Coskewness betas are much more pronounced in the period that includes the crisis than during the calm period before. The histogram of actual dividend cuts (relative to futures-implied expectations) shows that, similar to the Euro Stoxx 50, several companies indeed omit their dividend payments in 2020 entirely.

In Appendix B, Tables B1 and B2 provide further evidence on drawdowns of 27 FTSE 100 constituent companies for which there are listed single stock dividend futures available. The dividend drawdowns appear of similar magnitude as stock drawdowns in the first quarter, hiding the more extreme values of the first trading days of April. Still, drawdown betas are statistically indistinguishable from 1 , thereby further supporting our findings that, in contrast to the notion of sticky dividends, the present value of near-term dividends crashed at least as much as the overall stock prices during the pandemic crisis. 


\section{FIGURE 7}

\section{Evidence for the U.K.}

Graph A of Figure 7 shows the FTSE 100 market excess return index in comparison to the corresponding dividend futures with maturities 2020 and 2021 from Jan. 1, 2019 to Dec. 18, 2020. Graph B shows the (cumulative) present values of the dividend futures with constant maturities from 1 to 5 years, expressed as a fraction of index value. We construct constant-maturity contracts as time-weighted averages of adjacent annual dividend futures. Graph $\mathrm{C}$ shows the coskewness betas $\beta_{j}^{\text {cosk }}$ of constant-maturity dividend futures with maturities from 1 to 5 years, obtained from a regression of weekly dividend futures excess returns on squared market excess returns: $r x_{i, t}=\alpha_{i}+\beta_{i}^{\text {cosk }} r x_{m, t}^{2}+\varepsilon_{i, t}$. Graph D plots the frequency of actually realized dividend cuts in the year 2020 for the 27 FTSE 100 member companies for which single stock dividend futures contracts are available. A value of 1 corresponds to a $100 \%$ cut of dividends relative to the futures-implied expectation at the beginning of the year. Negative values correspond to dividend increases. Values $<-1$ are truncated. Sources: Bloomberg and Refinitiv Eikon.
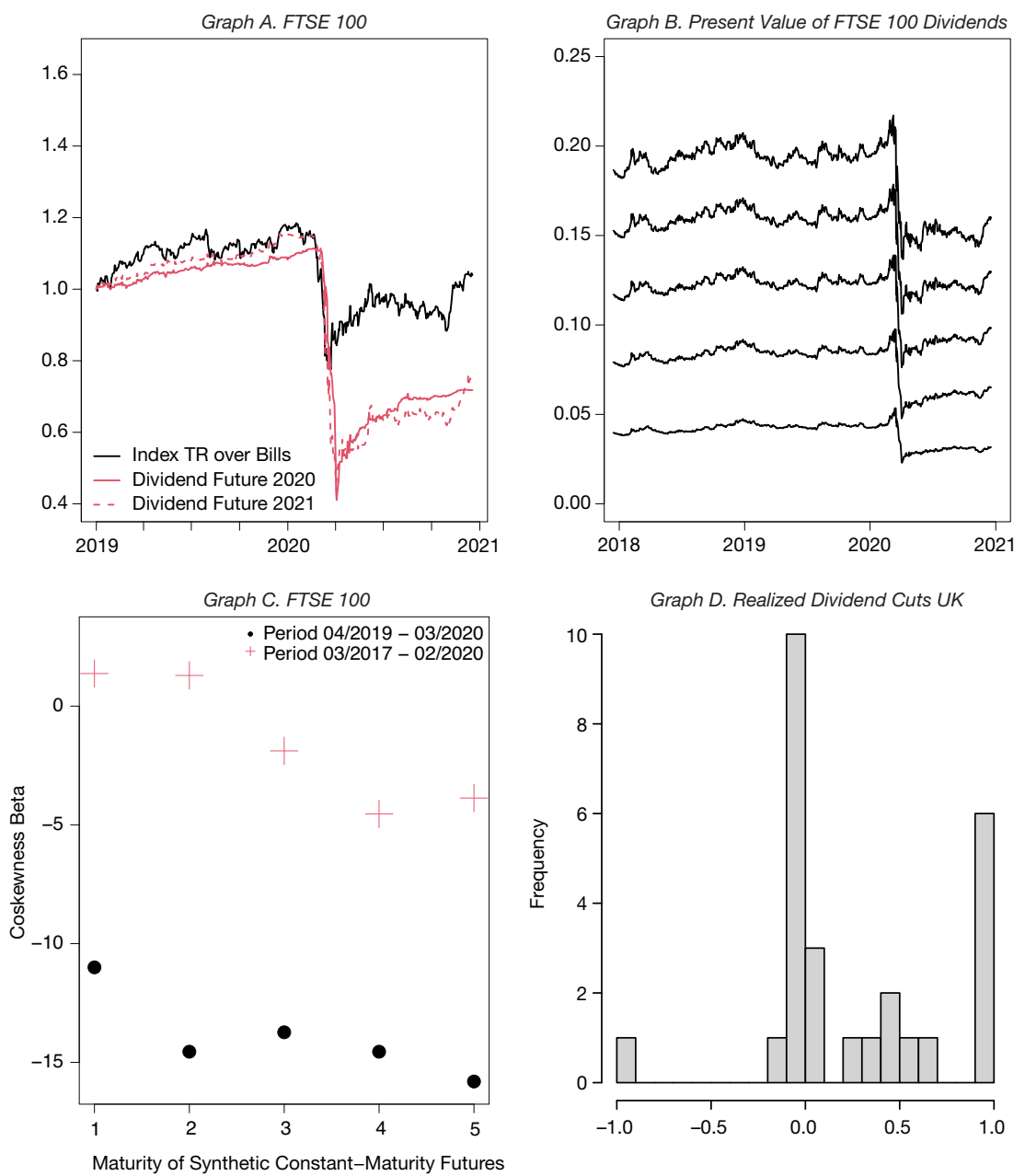

\section{B. Excluding Financials}

As discussed in Section $\mathrm{V}$, the crash in the present value of near-term dividends is more pronounced within the financial sector than for the overall market. However, Figure 6 shows that a substantial drop in the value of near-term dividends is also observed for nonfinancial firms. Table 9 provides more information on the 
interaction between stock prices and the dynamics of the value of near-term dividends for nonfinancial firms, exploiting cross-sectional data. As shown in Table 9, even for this subsample, the betas of a regression of dividend futures drawdowns on stock price drawdowns are around 1 in the first quarter of 2020, with positive alphas. This implies that dividend drawdowns were, on average, more pronounced than stock drawdowns. When re-estimating the regression for the entire year 2020 for nonfinancials, one still finds positive and significant alphas, but the betas are now estimated imprecisely.

\section{Conclusion}

This article shows that, contrary to the common belief that the value of nearterm dividends is less volatile than share prices, the opposite was true during the onset of COVID-19. Especially, during the first quarter of 2020, the value of nearterm dividend futures dropped more than the overall market for the S\&P 500, for the Euro Stoxx 50, and for the FTSE 100. We find that this excess drop was not fully reversed over the full year 2020. We also document that near-term dividend futures exhibit negative coskewness betas, especially when data until the end of 2020 are included. The drop in the value of near-term dividends relative to overall stock prices is heterogeneous across firms: It is positively related to firms' debt-to-totalassets ratio and to the degree to which their operations are exposed to the pandemic and negatively to their operating cash flows and the coskewness of their stock returns. We also document that the drop in the value of near-term dividends to stock prices was particularly large in the financial sector, which was also exposed to regulatory dividend restrictions after the onset of the COVID-19 pandemic. We further document that firms that cut their dividends by at least $50 \%$ experienced a substantial and significant increase in their exposure to market risk.

Overall, it appears that dividend smoothing breaks down in disaster states. The evidence presented offers a possible explanation for the puzzle that near-term dividend futures exhibit anomalously high risk premia. These risk premia seem to come with negative coskewness and exposure to disaster risk. The fact that the negative coskewness seems to be reinforced by regulatory restrictions imposed on dividends and seems to make dividend cuts even more severe and therefore may lead to higher expected costs of capital is something regulators should be aware of. 
Our findings suggest several avenues for future research. In particular, it would be interesting to analyze which tradeoffs imply smooth dividends in normal states, but heavy dividend cuts in states of distress. Our empirical findings seem consistent with dividend theories, where the cost and benefits of paying out dividends do not change with the same proportionality when a firm's economic outlook changes significantly. Furthermore, it would be interesting to understand the interaction between firms' dynamic dividend policies and their cost of capital. Specifically, one would like to know whether there is indeed a relation between risk premia and firm's dividend adjustments in bad times. We will explore these questions in future work.

\section{Appendix A. Betas of Constant-Maturity Dividend Futures}

In Table A1, we provide the betas of constant-maturity dividend futures with maturities from 1 to 5 years, estimated using weekly data from Mar. 2017 to Feb. 2020.

\section{TABLE A1}

Betas of Constant-Maturity Dividend Futures on Equity Indices

\begin{tabular}{|c|c|c|c|}
\hline & $\beta$ & SE & Adj. $R^{2}$ \\
\hline \multicolumn{4}{|l|}{ Euro Stoxx 50} \\
\hline Div. future const. 1-yr mat. & 0.1415 & 0.0200 & 0.3028 \\
\hline Div. future const. 2-yr mat. & 0.4783 & 0.0420 & 0.5321 \\
\hline Div. future const. 3-yr mat. & 0.7604 & 0.0405 & 0.7564 \\
\hline Div. future const. 4-yr mat. & 0.9567 & 0.0429 & 0.8146 \\
\hline Div. future const. 5-yr mat. & 1.0669 & 0.0471 & 0.8195 \\
\hline \multicolumn{4}{|l|}{ S\&P 500} \\
\hline Div. future const. 1-yr mat. & 0.0452 & 0.0221 & 0.0273 \\
\hline Div. future const. 2-yr mat. & 0.1753 & 0.0266 & 0.2724 \\
\hline Div. future const. 3-yr mat. & 0.2775 & 0.0355 & 0.3473 \\
\hline Div. future const. 4-yr mat. & 0.3686 & 0.0409 & 0.4150 \\
\hline Div. future const. 5-yr mat. & 0.4111 & 0.0453 & 0.4187 \\
\hline \multicolumn{4}{|l|}{ FTSE 100} \\
\hline Div. future const. 1-yr mat. & 0.0664 & 0.0381 & 0.0177 \\
\hline Div. future const. 2-yr mat. & 0.2109 & 0.0597 & 0.0922 \\
\hline Div. future const. 3-yr mat. & 0.3487 & 0.0574 & 0.2408 \\
\hline Div. future const. 4-yr mat. & 0.4563 & 0.0633 & 0.3110 \\
\hline Div. future const. 5-yr mat. & 0.4881 & 0.0703 & 0.2949 \\
\hline
\end{tabular}

\section{Appendix B. Further Evidence for the U.K.}

Appendix B provides summary statistics on the cumulative drawdowns of single stock dividend futures and individual stocks from the U.K. in Table B1. Table B2 reports the results from cross-sectional drawdown regressions of U.K. firms, where we regress the cumulative drawdown of single stock dividend futures on the cumulative drawdown of the corresponding individual stock. 


\section{Drawdown Summary Statistics U.K.}

Table B1 provides summary statistics on the cumulative drawdowns of single stock dividend futures and cumulative drawdowns of individual stocks. The sample consists of all 27 FTSE 100 companies that have listed single stock dividend futures. Positive numbers correspond to drawdowns, whereas negative numbers indicate positive cumulative stock or dividend futures performance. Source: Bloomberg.

\begin{tabular}{|c|c|c|c|c|c|c|}
\hline & Min & P25 & Median & Mean & $\underline{\mathrm{P} 75}$ & Max \\
\hline \multicolumn{7}{|c|}{ Cumulative Drawdown During Q1 2020} \\
\hline Individual dividend futures 2020 & -0.16 & 0.00 & 0.00 & 0.16 & 0.30 & 0.71 \\
\hline Individual dividend futures 2021 & -0.33 & 0.00 & 0.00 & 0.12 & 0.17 & 0.86 \\
\hline U.K. stocks & -0.00 & 0.10 & 0.23 & 0.26 & 0.37 & 0.73 \\
\hline \multicolumn{7}{|c|}{ Cumulative Drawdown During the Year 2020} \\
\hline Individual dividend futures 2020 & -1.42 & -0.04 & 0.01 & 0.25 & 0.61 & 1.00 \\
\hline Individual dividend futures 2021 & -1.42 & 0.00 & 0.11 & 0.19 & 0.53 & 1.00 \\
\hline U.K. stocks & -0.26 & 0.03 & 0.13 & 0.15 & 0.27 & 0.62 \\
\hline
\end{tabular}

\section{Cross-Sectional Drawdown Regression U.K.}

Table B2 provides results from the following regression analysis: $D D_{\text {div }}=\alpha+\beta D D_{\text {stock }}+\varepsilon$, where $D D_{\text {div }}$ are the cumulative drawdowns of single stock dividend futures, and $D D_{\text {stock }}$ are the cumulative drawdowns of the corresponding individual stocks. SE denotes the standard error of the coefficient. The sample includes the 27 companies from the FTSE 100 index that have exchange-listed single stock dividend futures. Source: Bloomberg.

\begin{tabular}{|c|c|c|c|c|c|}
\hline & $\beta$ & SE & $\alpha$ & SE & Adj. $R^{2}$ \\
\hline \multicolumn{6}{|l|}{ Cumulative Drawdown During Q1 2020} \\
\hline DD single stock 2020 dividend futures U.K. & 0.63 & 0.25 & -0.01 & 0.08 & 0.18 \\
\hline DD single stock 2021 dividend futures U.K. & 0.56 & 0.23 & -0.03 & 0.07 & 0.16 \\
\hline \multicolumn{6}{|l|}{ Cumulative Drawdown During the Year 2020} \\
\hline DD single stock 2020 dividend futures U.K. & 1.24 & 0.48 & 0.06 & 0.12 & 0.18 \\
\hline DD single stock 2021 dividend futures U.K. & 1.13 & 0.38 & 0.01 & 0.10 & 0.23 \\
\hline
\end{tabular}

\section{References}

van Binsbergen, J. H.; W. Hueskes; R. Koijen; and E. B. Vrugt. "Equity Yields.” Journal of Financial Economics, 110 (2013), 503-519.

van Binsbergen, J. H., and R. Koijen. "The Term Structure of Returns: Facts and Theory." Journal of Financial Economics, 124 (2017), 1-21.

Bonaimé, A.; J. Harford; and D. Moore. "Payout Policy Trade-Offs and the Rise of 10b5-1 Preset Repurchase Plans.” Management Science, 66 (2020), 2762-2786.

Brav, A.; J. R. Graham; C. R. Harvey; and R. Michaely. "Payout Policy in the 21 st Century." Journal of Financial Economics, 77 (2005), 483-527.

Brennan, M.. "A Note on Dividend Irrelevance and the Gordon Valuation Model." Journal of Finance, 26 (1971), 1115-1121.

Brennan, M. "Stripping the S\&P 500 Index." Financial Analysts Journal, 54 (1998), 12-22.

Cejnek, G., and O. Randl. "Risk and Return of Short-Duration Equity Investments." Journal of Empirical Finance, 36 (2016), 181-198.

DeAngelo, H.; L. DeAngelo; and R. M. Stulz. "Dividend Policy and the Earned/Contributed Capital Mix: A Test of the Life-Cycle Theory." Journal of Financial Economics, 81 (2006), 227-254.

Gonçalves, A. S. "Reinvestment Risk and the Equity Term Structure." Journal of Finance, 76 (2021), 2153-2197.

Gormsen, N. J., and R. S. J. Koijen. "Coronavirus: Impact on Stock Prices and Growth Expectations." Review of Asset Pricing Studies, 10 (2020), 574-597.

Harvey, C. R., and A. Siddique. "Conditional Skewness in Asset Pricing Tests." Journal of Finance, 55 (2000), 1263-1295. 
Kraus, A., and R. H. Litzenberger. "Skewness Preference and the Valuation of Risk Assets." Journal of Finance, 31 (1976), 1085-1100.

Leary, M. T., and R. Michaely. "Determinants of Dividend Smoothing: Empirical Evidence.” Review of Financial Studies, 24 (2011), 3197-3249.

Lintner, J. "Distribution of Incomes of Corporations among Dividends, Retained Earnings, and Taxes." American Economic Review, 46 (1956), 97-113.

Manley, R., and C. Mueller-Glissmann. "The Market for Dividends and Related Investment Strategies." Financial Analysts Journal, 64 (2008), 17-29.

Modigliani, F., and M. H. Miller. "Dividend Policy, Growth, and the Valuation of Shares." Journal of Business, 34 (1961), 411-433.

Ramelli, S., and A. F. Wagner. "Feverish Stock Price Reactions to COVID-19." Review of Corporate Finance Studies, 9 (2020), 622-655.

Schneider, P.; C. Wagner; and J. Zechner. "Low-Risk Anomalies?” Journal of Finance, 75 (2020), 2673-2718.

Wu, Y. "What's Behind Smooth Dividends? Evidence from Structural Estimation.” Review of Financial Studies, 31 (2017), 3979-4016. 